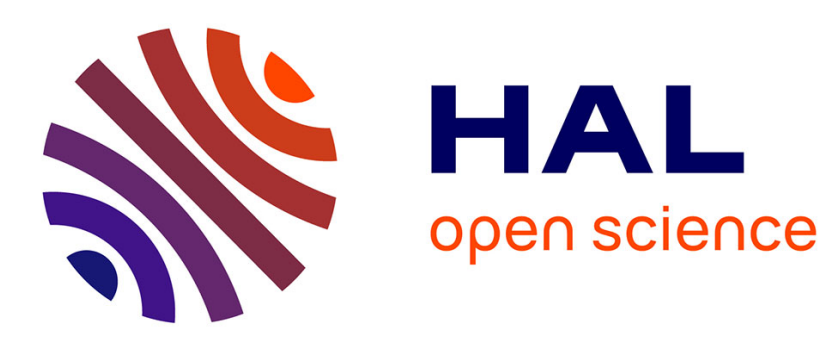

\title{
Supporting experimental methods in Information System research
}

Nadine Mandran, Sophie Dupuy-Chessa

\section{To cite this version:}

Nadine Mandran, Sophie Dupuy-Chessa. Supporting experimental methods in Information System research. 12th IEEE International Conference on Research Challenges in Information Science RCIS'2018, May 2018, Nantes, France. hal-01903302

\section{HAL Id: hal-01903302 \\ https://hal.science/hal-01903302}

Submitted on 24 Oct 2018

HAL is a multi-disciplinary open access archive for the deposit and dissemination of scientific research documents, whether they are published or not. The documents may come from teaching and research institutions in France or abroad, or from public or private research centers.
L'archive ouverte pluridisciplinaire HAL, est destinée au dépôt et à la diffusion de documents scientifiques de niveau recherche, publiés ou non, émanant des établissements d'enseignement et de recherche français ou étrangers, des laboratoires publics ou privés. 


\title{
Supporting experimental methods in Information System research
}

\author{
Nadine Mandran, Sophie Dupuy-Chessa \\ Univ. Grenoble Alpes, CNRS, Grenoble INP, LIG, \\ 38000 Grenoble, France \\ Nadine.mandran@univ.grenoble-alpes.fr, Sophie.dupuy-chessa@univ-grenoble-alpes.fr
}

\begin{abstract}
Computer scientists in information system encounter difficulties in leading research when they must consider human aspects, especially while designing users centred experiments. In order to guide them in this difficult task, this paper presents the THEDRE research process and the MATUI decision tree. It focuses on MATUI which aims at helping in the selection of the most appropriate user centred experimental methods thanks to researchers oriented criteria. MATUI also considers a categorisation and a description of experimental methods. THEDRE and MATUI are supported by a website to practically guide researchers. They are the results of 10 years of work in information system experiments. 16 researchers have evaluated them during 2 focus groups.
\end{abstract}

Keywords-experimental support, user centered approach, qualitative method, quantitative method, making-decision tree

\section{INTRODUCTION}

Information systems (IS) are socio-technical systems. By nature, they must consider individuals and their working environment. So research in IS needs to include humans in the process of building and evaluating scientific knowledge. But addressing the human question can be difficult for several reasons: 1) computer scientists are rarely trained to social and human sciences methods, 2) social scientists such as specialist in experiments, i.e. methodologists, do not know the IS concepts and models, 3) information systems are based on complex and abstract concepts and 4) end-users are fickle (inconstant); their opinions and perceptions can evolve even in a contradictory manner. The problem is above all a problem of realizing experiments in a human context with a research goal. It brings many questions such as: which data must be collected? Involving which users? For what purpose? How many users must be involved? Addressing this problem, our research question concerns the guidance of researchers in building users experiments for IS research i.e helping them to select the appropriate user centred experimental methods and define their experiments.

To answer this question, two approaches are proposed. On the one hand, some research methodologies, like Design Science, exist [1][2][3]. They include end-users characteristics. But they lack an operational process and decision support tools to choose the most appropriate methods for user centred experiments. On the other hand, there are lots of articles and books about social methods to approach human behaviours and opinions [4] [5][6][7]. The best known of them are interviews, focus group or questionnaires. However even if they are central for the research success, they are not integrated in a global process so that it is difficult to choose the most appropriate ones.

The lack of connection between high-level research methodologies and practical experimental methods lead us to propose a formalized process, called THEDRE [8], with a decision-making step dedicated to the selection of users centred experimental methods. This paper will focus on the decision making step and its tool support. Our proposal relies on more than 10 years in supporting IS researchers in the realization of their experiments. It was built according to the participatory observation method [9] and evaluated by two focus groups.

The next section presents work related to research methodologies and user centred experimental methods. Section 3 describes our proposal with an overview of the THEDRE research process and its step for building experiments and with conceptual tools for guiding researchers in their experimental practices. Section 4 explains the building and the evaluation of our proposal. The last section summarizes this work and proposes some future work.

\section{RELATED WORK}

Our problem is related to the researchers' guidance particularly in designing users centred experiments. So it is related to research methodologies and to methods for experiments. It can also be inspired from industrial practices. So this section presents these three of aspects that are relevant for leading user centred experimental research in IS.

\section{A. Research Methodologies}

Mainly two approaches have been used in the IS domain: Action Design Research [10] and Design Science [11] [12]. Design Science is composed of three cycles: 1) the relevance cycle to link research with its environment, 2) the rigor cycle which relates the research activities with existing knowledge in research, experiences and expertise and 3) the third cycle, that deals with the 
building of an artefact, its evaluation and its improvement. These three cycles are a first manner to guide research by providing a global process. However the descriptions of their process are not precise enough to guide IS researchers particularly in building their user centred experiments.

From these seminal works, some authors propose enhancements for improving the epistemological posture [3] or to enhance the pertinence cycles [13]. For instance Insider action Design Research [14] is interesting for the central place of experimentation and the reflection about the role of researcher/practitioner. However the experimental part of the process or the researcher role are not detailed.

Another extension of Design Science is particularly relevant as it aims at improving the operational process. According to K.Peffers et al [13], Design Science is not adopted in the information system community because it only proposes a mental model and does not propose a real process to follow. To avoid this drawback, they present a six steps process: "identification of problem, goals of solution, design and development, demonstration, evaluation and communication". This proposal is interesting because it offers a process detailed enough to follow the Design Science approach, making it more operational. However the experimental process is not explicit.

Finally some papers tried to help in conducing the experimental process. [24] extends the Design Science approach with some decision questions to help in analysing the research problem and data analysis. [25] proposes some combinations of Design Science artifact types (algorithm, construct, Framework, instantion, method, model) and artifact evaluation methods (logical argument, prototype, case study, tecnical experiment...) from the study of 148 articles. In a similar way, [26] elaborates a framework where support is proposed from a matrix of evaluation strategies, including the choice of ex ante (prior to artifact construction) versus ex post evaluation (after artifact construction) and naturalistic (e.g., field setting) versus artificial evaluation (e.g., laboratory setting).

None of these research methodologies provide a fine grain practical level of description of the experimental part of the research process. In the industry, more practical approaches are proposed for exploring users' viewpoints.

\section{B. Industrial practices}

Industrial practices for approaching human behaviours and opinions are mainly based on the user centred-design approach. It is described in the ISO 9241210 standard [15]. It aims at improving users' interaction. It describes software development as a cycle integrating users at the beginning of the process. User centred design proposes three main phases: analysis, design and evaluation.

The analysis phase studies users' practices, their environment, their needs and their expectations. It uses qualitative approaches such as semi-structured interviews or in-situ observations.

The second step is the design. It aims at building the system in collaboration with users. One method often used is the focus group where several users build something together before debriefing to collect their opinions and improvement suggestions.

The last phase, evaluation, permits to measure some criteria such as usability with users. Here experimental methods are quantitative.

The user centred approach has the advantages of having a rather precise process. With its well-defined goal for each phase, some user centred experimental methods can be easily recommended. However there is no guidance in the selection of any method inside a phase. This can be very tricky if one considers the numbers of existing methods for data production.

\section{Qualitative and Quantitative approaches}

User centred experimental methods must produce data to analyse human opinions or behaviour. So they can be seen as methods for data production. Two main approaches can be used for experimental data production.

First, « qualitative methodologists have described three major purposes for research: to explore, explain or describe a phenomenon. .... They build rich descriptions of complex circumstances that are unexplored in the literature. Others are explicitly explanatory: they show relationships between events (frequently as perceived by the participants in the study) and the meaning of those relationships" [7]. It focuses on the meaning and the observation of a phenomenon in ecological or experimental situations. It aims at identifying existing phenomenon and at understanding their execution. Classical qualitative methods are focus groups or interviews. The size of the sampling is relatively small (between 15 to 25 individuals) even if it depends on the experimental goals and on the field constraints.

Creswell [4] classifies qualitative methods into 4 groups: 1) observations in which researcher takes note about people activities, 2) Interviews where people are interviewed in face to face or in group meetings., 3) Document analysis where documents produced during the research process are studied, 4) Audio and visual material (e.g. pictures or sound record). This classification is interesting as it avoids getting lost in the quantities of existing methods. However it brings confusion between the methods and their supporting materials. For instance, audio and video material can be produced during interviews. So a more operational classification of methods is required.

Secondly, quantitative methods are defined in sociology as "quantitative research methods are methods dealing with numbers and anything that is measurable in a systematic way of investigation of phenomena and their relationships. It is used to answer questions on relationships with measurable variables with an intention to explain, test, predict and control a phenomena"[4]. They permit to measure opinions or behaviours thanks to tools such as questionnaires or activity traces.

The two approaches have different goals. But they are complementary as qualitative methods permit to understand phenomenon and quantitative ones allow quantifying. Both of them propose generic methods that can be used in various situations. If this flexibility is an advantage, it also induced some knowledge to select the most appropriate methods. 
In conclusion, research methodologies are too coarse grain to provide guidance for conducing experimental activities. User Centred Design approach is interesting to involve users in a design process and to split the process into precise steps (analysis, design, evaluate) but it needs to be adapted to IS research which does not follow a classical design cycle. The methods for producing experimental data are numerous but there is no guidance to help in the choice of the most appropriate methods in a particular situation. The goal of this paper is to address this lack by providing a fine-grained research process with support for selecting and realizing users centred experimental activities.

\section{THE THEDRE RESEARCH PROCESS AND ITS MATUI DECISION TREE}

Our contribution proposes a fine grain process [8] for IS research, called THEDRE. Inside this process, the experimental subprocess is detailed and supported by a decision tree to guide researchers in the selection of an appropriate user centred experimental method. We name the decision tree, MATUI for Making-decision Tree to Involve Users.

\section{A. THEDRE concepts}

Before starting the THEDRE description, we must concern ourselves with tools that will be built and evaluated during an experiment for IS research. In such research, the goal is to produce an instrument, which carries some scientific knowledge and relies on some activable tools. An activable tool represents some scientific knowledge in a form that can be used by users. It is the medium between users and the scientific knowledge. It can be either dynamic if it is supported by a tool (e.g. a prototype) or static (e.g. a dictionary of concepts or a model) if there is no automatic tool support. If it is too complex, it can be decomposed into components called "activable components". They are the parts of the activable tool, but they can be isolated to be built and evaluated separately. For instance, let's consider a PhD work [23] that studies how allowing users to participate in the modelling of their business processes. The scientific knowledge concerns the identification of concepts for designing business processes with users. It is concretized in several activable tools: 1) a process to involve users in the modelling of their processes, 2) a simplified business process modelling language for end-users and 3 ) a tool to allow users to collaborate and design their process. The business process modelling language is composed of several activable components: a dictionary of concepts, a metamodel and a concrete syntax.

Activable components/tools can take benefits from users' studies as they allow researchers to better understand users, to make them actors in the research process or to evaluate it. In such research processes (Fig. 1), users contribute via experiments that must provide significant data to researchers to propose activable tools reflecting scientific knowledge. So the process for producing experimental data is very important. The next sections describe our research process, THEDRE, and its steps related to user centred experiments.

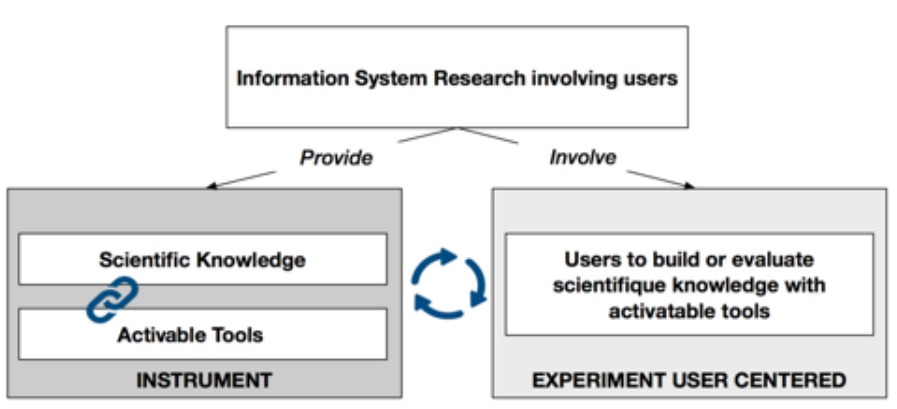

Fig 1. Features of Information System Research involving users: composed with scientific knowledge linked with activable tools (link symbol) and built with several iterations (cycle symbol)

\section{B. The THEDRE process and its experimental phase}

The THEDRE research process is structured following 4 cycles (Fig. 2) involving three kinds of internal actors (researchers, developers and methodologists) and external actors, such as end-users, stakeholders or practitioners. In the rest of the paper, any external actor will be referred as user.

THEDRE regroups the 3 cycles of Design into a continuous quality improvement cycle proposed by Deming [16] : Plan Do Check Act (PDCA): Plan for research planner, Do for making developments and conducing experiments, Check for assessing results and Act which allows researchers to construct knowledge regarding assessments and to take the decision to start a new cycle or to communicate on results. To illustrate these four steps, we will consider the example of the study of business process modelling by users. So more precisely, the THEDRE process is structure as follows:

- PLAN: it focuses on research construction; it sets targets to achieve and it steers actions concerning development, experiments, and communication. During the first cycle, the research question and the experimental targets must be set. During the other cycles, the research question can be refined and other experimental targets can be defined. In our example, the research question concerns the way to involve users in the modelling of their business processes. So user centred experiments were realized to explore how users express their processes, to build with users an application supporting their process modelling and to evaluate it. User centred experiments were planned to explore how users express their processes, to build with users a prototype supporting their process modelling and to evaluate it.

- DO: it focuses on the development and the experiments to carry out, to build and to assess the research instrument. It corresponds to the THEDRE "Experiment" subprocess. For instance, several experiments were realized to build the application: one of them concerned the creation of the business modelling language, one the design of the prototype supporting users modelling and one for the evaluation of the prototype.

- CHECK: this step aims at assessing the experimental results and at controlling targets. Researcher checks whether the research targets are achieved. This step is 


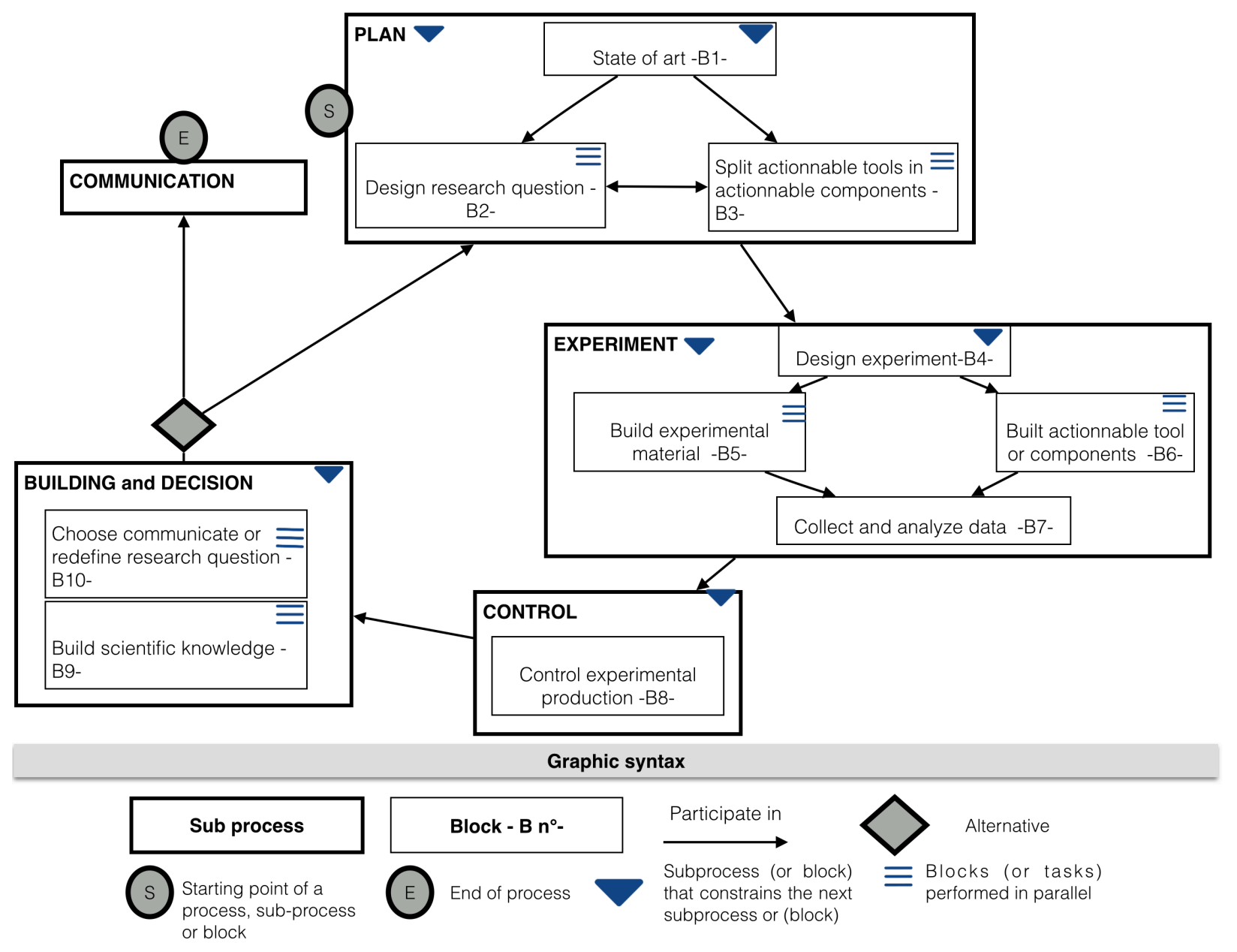

Fig. 2. The THEDRE process

named "Control" in THEDRE. In our example, the evaluation of the prototype was not successful.

- ACT: during this subprocess, some scientific knowledge is created from the experimental results and its limits. It is time for the researcher to make a decision about the continuation of his/her work on the research question and about communicating results. Depending on these answers, another PCDA cycle can start. The "Act" step of the Deming's wheel corresponds to the THEDRE "Building and decision» sub process. In our example of business process modelling with users, as the prototype was badly evaluated, the decision was taken to restart a research cycle to propose another prototype with an experiment to design the prototype with users.

A complete description of the THEDRE process is proposed in [17]. As this paper aims at helping researchers in their experimental activities, we focus on the "Experiment" subprocess, which is divided into three blocks: "Design experiments", "Create and test the experimental material" and "Produce and analyse data and report results". 
The "design experiment" block concerns the difficult task of building experiments and selecting appropriate data production methods. It is composed of seven tasks (Fig. 3): T1: "Share between internal actors the added value of research". This task allows internal actors to well understand the research objectives; T2: "Define goals of experiment", all actors collaborate to define precisely the experiment objectives; T3: "Write question or hypothesis" in order to precisely define data to acquire during the experiments; T4:"Identifiy measures and data to produce" so as to being able to answer the question or validate the hypothesis; T5: all actors "determine ranges of possible data values"; T6 whose objective is the choice of the method for data production; T7 which defines the measures and data to compute goal indicators.

Among these tasks, choosing a data production method (T6) is particularly difficult as it involves people. It requires specialist competencies in social science methodologies. It also depends on the state of the activable tool (will the user be able to use the tool or not?) as well as on what the researcher knows about the user, her 'activity' and her context. It also depends of the goal of the experiment.
To help researchers in the difficult task of choosing an appropriate data production method, we propose the MATUI decision tree (Making-decision Tree to Involve Users) described in the next subsection.

\section{The MATUI decision tree}

The key question is related to the need to understand or to quantify. However this is not precise enough to provide researchers fine grain recommendations. That's why we propose the MATUI decision tree. MATUI uses a classification of users centred experimental methods that is described first.

\section{1) Classification and preconisation of methods}

As explained in the related work section, many articles and books present methods for producing user centred experimental data. Our goal is not to detail them, but to provide guidelines to select the most appropriate ones for an IS research situation. So our proposal starts by characterizing methods so as to be able to recommend one of them thanks to the MATUI decision tree.

First of all, methods for producing user centred data can be classified in two approaches [4]: 1) qualitative approaches to

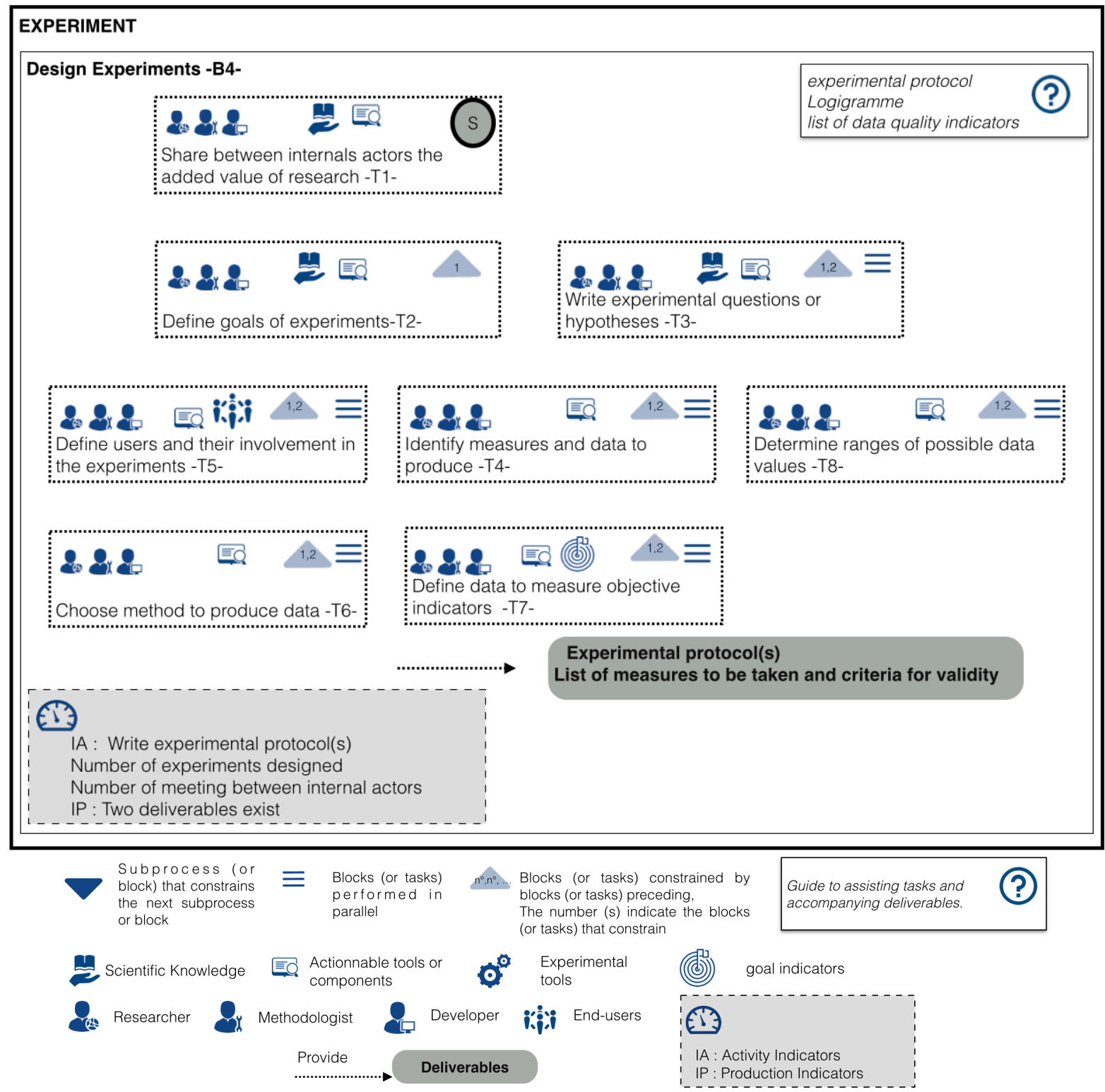

Fig.3. Block 'Design experiment' of the sub process « Experiment » and graphical syntax. 
collect information or observe phenomenon even if there can seem tiny; 2) quantitative approaches to quantify phenomenon or to validate/invalidate hypotheses. To enrich this existing classification, we propose a table (Fig. 4) synthesizing these two approaches through 4 attributes - sample, method of data production, data collected, and data analysis:

\section{- Qualitative approaches}

Sampling: as the goal is to identify possible cases by observing a maximum of behaviours or by understanding a maximum of points of view, a number of participants between 15 and 25 persons with very different profiles [18],[4],[5] can be favoured.

Methods of data production: we split them in three categories 1) observational methods to observe a situation, an activity in situ, during a short or a long period, 2) interviews to discuss in depth with individual users, 3) focus group to confront or to produce ideas with several users.

Produced data: 1) audio or video records, 2) users' productions such as schemas produced during the experiment, 3) all material available in the field to understand users.

4) Data analysis relies on methods to analysis speech, both in a lexical and a semantical manners.

\section{- Quantitative approaches}

Sampling : the goal is to validate or invalidate phenomenon in a significant manner. So statistical sampling procedures or experimental plans must be planned [19].

Methods of data production: we split them in 3 categories: 1) survey to ask precise question to users (e.g. satisfaction survey, System Usability Scale [20]) , 2) data activity capture with user (e.g. such as traces), 3) data capture without user ${ }^{1}$ (e.g. system performance, duration of an algorithm)

Data produced can be 1) qualitative variable ${ }^{2}$ in the sense that they do not refer to a standard unit (e.g. qualitative variable gender: male/female or professional categories) 2) quantitative variables if they represent quantities and refer to standards (e.g. weight, duration).

Data analysis is based on statistics with methods such as hypothesis test or clustering.

1 some data provided by application can be useful to understand users' behaviours

2 Qualitative has 2 meanings: one for approaches and one for variables.

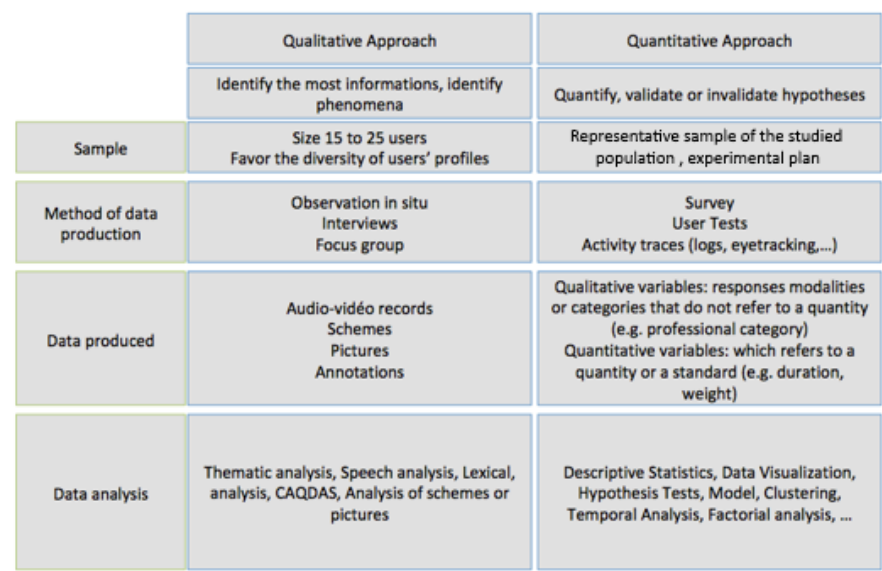

Fig. 4 Qualitative and quantitative approaches overview

In complement to the distinction qualitative/quantitative approach, we propose 11 categories of user centred experimental methods (Fig. 5.1, 5.2 and 5.3). These categories are based on the most common user centred experimental methods: probes, observations, interviews, surveys, focus groups and user tests. Depending on the availability of an activable tool, they have been refined and sometimes split into several categories. For instance, interviews can be declined in different manner depending on the existence of an activable tool. If the tool is dynamic, users can interact with it during the interview and traces can be recorded (method M10 fig. 5.3). If the tool is static, it must be provided to users for feedbacks (method M5 fig. 5.2). And if no activable tool exists (method M3 fig. 5.1), the interview will be based on questions about users' opinions and practices. Some variants of these methods are of course possible, but they will not impact the selection described in MATUI.

Categories of Methods M1 to M4 : when activatable tools do not exist

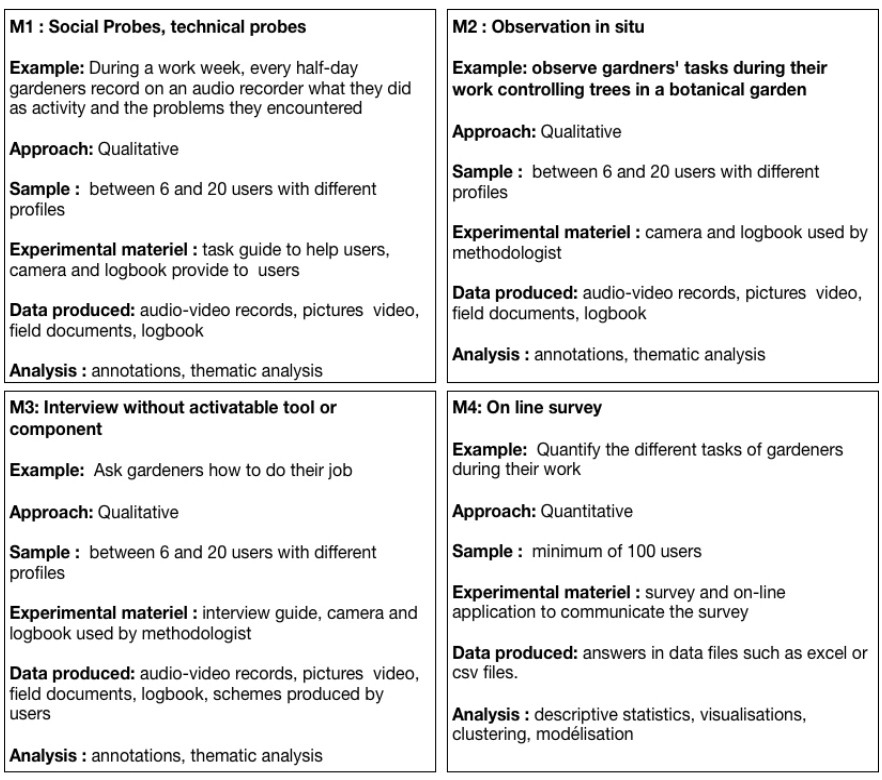

Fig.5.1. Categories of methods recommended when the activable tool or components do no exist 


\begin{tabular}{|c|c|}
\hline $\begin{array}{l}\text { M5: Interview with static activatable tool or } \\
\text { components }\end{array}$ & $\begin{array}{l}\text { M6: Focus-group with static activatable } \\
\text { components }\end{array}$ \\
\hline $\begin{array}{l}\text { Example: Ask gardeners about the terminology use } \\
\text { in their job with a concepts dictionnary (i.e. static } \\
\text { activatable component) }\end{array}$ & $\begin{array}{l}\text { Example: confront the gardener's ideas on the paper } \\
\text { mockup (i.e. static activatable tool) of their future mobile } \\
\text { application }\end{array}$ \\
\hline Approach: Qualitative & Approach: Qualitative \\
\hline $\begin{array}{l}\text { Sample : between } 6 \text { and } 20 \text { users with different } \\
\text { profiles }\end{array}$ & $\begin{array}{l}\text { Sample: } 8 \text { to } 10 \text { users by focus-groups - iterate at } \\
\text { least twice }\end{array}$ \\
\hline $\begin{array}{l}\text { Experimental materiel : interview guide, camera and } \\
\text { logbook used by methodologist, schemes, activatable } \\
\text { tool or component in static form }\end{array}$ & $\begin{array}{l}\text { Experimental materiel : focus-group guide, camera } \\
\text { and logbook used by methodologist, activatable tool or } \\
\text { component in static form }\end{array}$ \\
\hline $\begin{array}{l}\text { Data produced: audio-video records, pictures video, } \\
\text { field documents, logbook, schemes produced by } \\
\text { users }\end{array}$ & $\begin{array}{l}\text { Data produced: audio-video records, pictures video, } \\
\text { field documents, logbook }\end{array}$ \\
\hline Analysis : annotations, thematic analysis & Analysis : annotations, thematic analysis \\
\hline
\end{tabular}

\begin{tabular}{|l|}
\hline M7: Wizard of oz with simulation of activatable tool or \\
component \\
Example: a gardeners test in lab a simulation of the \\
mobile application (i.e. static activatable tool) \\
Approach: Qualitative and quantitative \\
Sample : between 6 and 20 users with different profiles \\
Experimental materiel : interview guide, camera and \\
logbook used by methodologist, simulation of static \\
activatable tool or component \\
Data produced: traces produced by the simulation audio- \\
video records, \\
$\begin{array}{l}\text { Analysis : annotations, thematic analysis and descriptives } \\
\text { statistics, visualisations }\end{array}$ \\
\hline
\end{tabular}

Fig.5.2. Categories of methods recommended when the activable tools or components are static

Categories of Methods M8 to M11 when activatable tool or components are dynamic

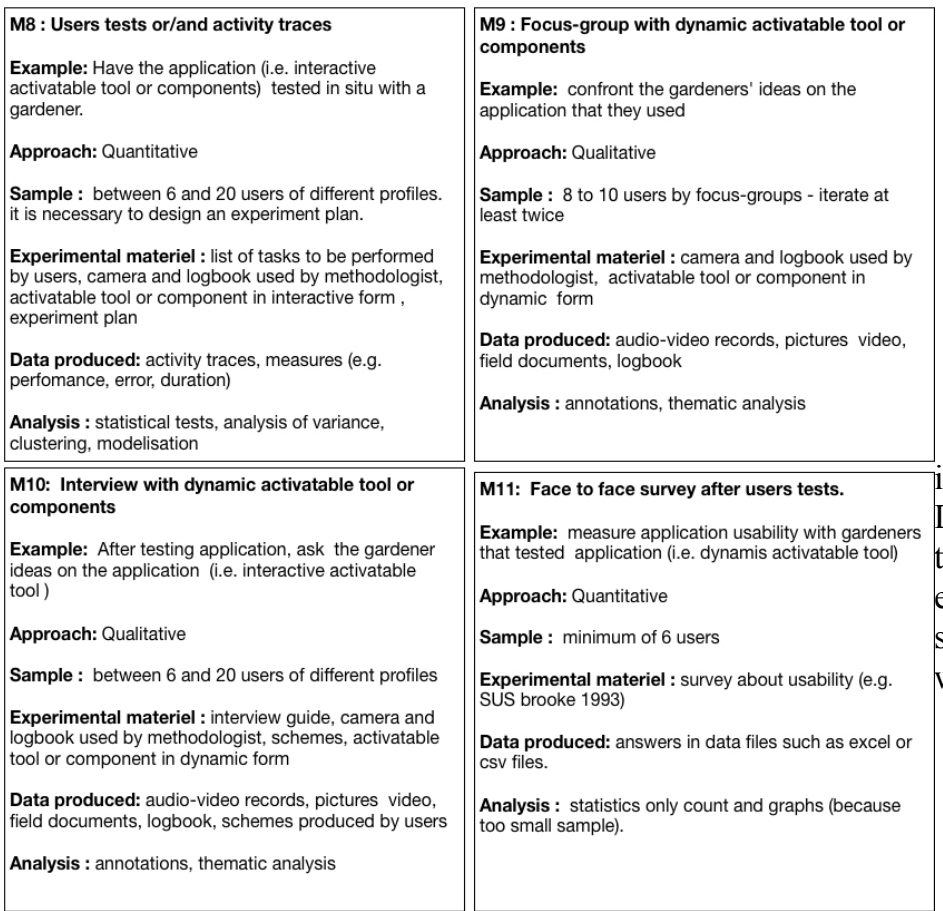

Fig.5.3. Categories of methods recommended when the activable tools or components are dynamic.
The classification of user centered experimental methods is completed by a model sheet. So each method description should contain precise information for IS researchers, without overloading them with irrelevant methodological information. So the description is composed of 7 attributes:

1) An example of use for the method. This example is provided at the very beginning to allow readers to situate the method in a context.

2) Type of approaches: qualitative or quantitative

3) Size of the sample

4) State of the component or tool to build or to evaluate. This attribute concerns the activable component or tool. It can have four values corresponding to four states: "it does not exist", "it is static", "it is static, but a simulation can be carried out", "it is dynamic". These states will allow researchers to understand why they need users for and what users can do with the component or tool.

5) Experimental material which is necessary to take measures (e.g. interviews guide, tracker)

6) Produced data (e.g. audio records, tracks, surveys' responses)

7) Type of analysis to realize

As an example, the method "Individual interview with static activable component(s)" classified as M5 (Fig. 5.2) is described as follows:

- Example: while creating a domain specific language for gardeners, question gardeners with a user interface mockup to check if all their business concepts are identified and if modifications are necessary.

- Qualitative approach

- Between 10 and 20 individuals

- Static activable component/tool

- Experimental material: interview guide

- Produced data: audio and video records, field documents, schemas

- Qualitative analysis: annotations of records, thematic analysis.

\section{2) Selection criteria}

To provide suitable guidance to IS researchers, the main important aspect is to identify their relevant choice criteria. During more than 10 years with IS researchers, we were able to observe IS researchers and their questions for designing experiments. So we propose 6 criteria centred on researchers so that they can select their user centred experimental methods without a methodologists' support:

- The state of the prototype component: "it does not exist", "it is static", "it is static, but a simulation can be carried out", "it is dynamic" (explain above)

- The researcher's prior knowledge of the user's activities or representations: "weak or partial knowledge", "'sufficient' knowledge"

- The duration of the experiment which can have three values: 1) long term experiment (e.g. when people are observed in their working environment during several 
days); even if the experimenter cannot be present, some tracking material such as log books, 2) Specific activities (e.g. observe a chirurgical operation), 3) A few minutes experiment (for instance for user interface testing).

- The user's contribution, which concerns user's involvement during the experiment. It is important to determine either if users have to express themselves one by one by making her/him doing a precise task or by collecting individual opinions or if several participants need to work together to confront their different points of view or to obtain a common representation.

- The experimental place: researchers must identify if the experiment can take place 1) in situ i.e. where users have their activities; an experiment in situ is interesting because the users' context can be observed, but experiments take longer time or 2) in laboratory, if the users' context is not available, shorter experiments can be realized, but users will have to go to the experimental place which is a constraint for users, 3 ) online when users are accessible only by the web for web survey for example.

- The number of potential available users to conduct experiments: "less than 100 people" and "more than 100 people" [19].

\section{3) Using the decision tree MATUI}

From these criteria, the decision tree MATUI (Fig. 6) can be followed by IS researchers to identify the most appropriate data production methods for their experimental situations. The questions of the tree are related to the criteria identified previously. The question answers permit to identify a category of methods for data production.

First, the experimental goals and a scientific proposal must have been defined. Reading Fig. 6 starts at the bubble START. The first question concerns the existence (or not) of an activable component. For instance, if there is no activable component, the next question is related to the accessibility of the business field (decision point "in situ"). If researchers have no access to the field, the next question is related to their users knowledge (decision point "good knowing of users"): if users are not enough precisely known, individual interview (M3) are proposed to better understand users.

In a similar manner, the MATUI decision tree can be used in the case of the existence of an activable component either if it is static or dynamic (decision point "AC: static or dynamic"). At the end, the MATUI's user obtains a list of user centred experimental methods appropriate to 'measure' human. It is then possible to select one or more methods for a single experiment depending on the factors listed above. For example, in the case of the definition of a business modelling language for stakeholders, an experimental step consists in understanding the way users can manipulate the language. There was a static activable tool, the language; many users can be involved to reach a consensus about the language concepts and its representation. So a focus group was chosen. 


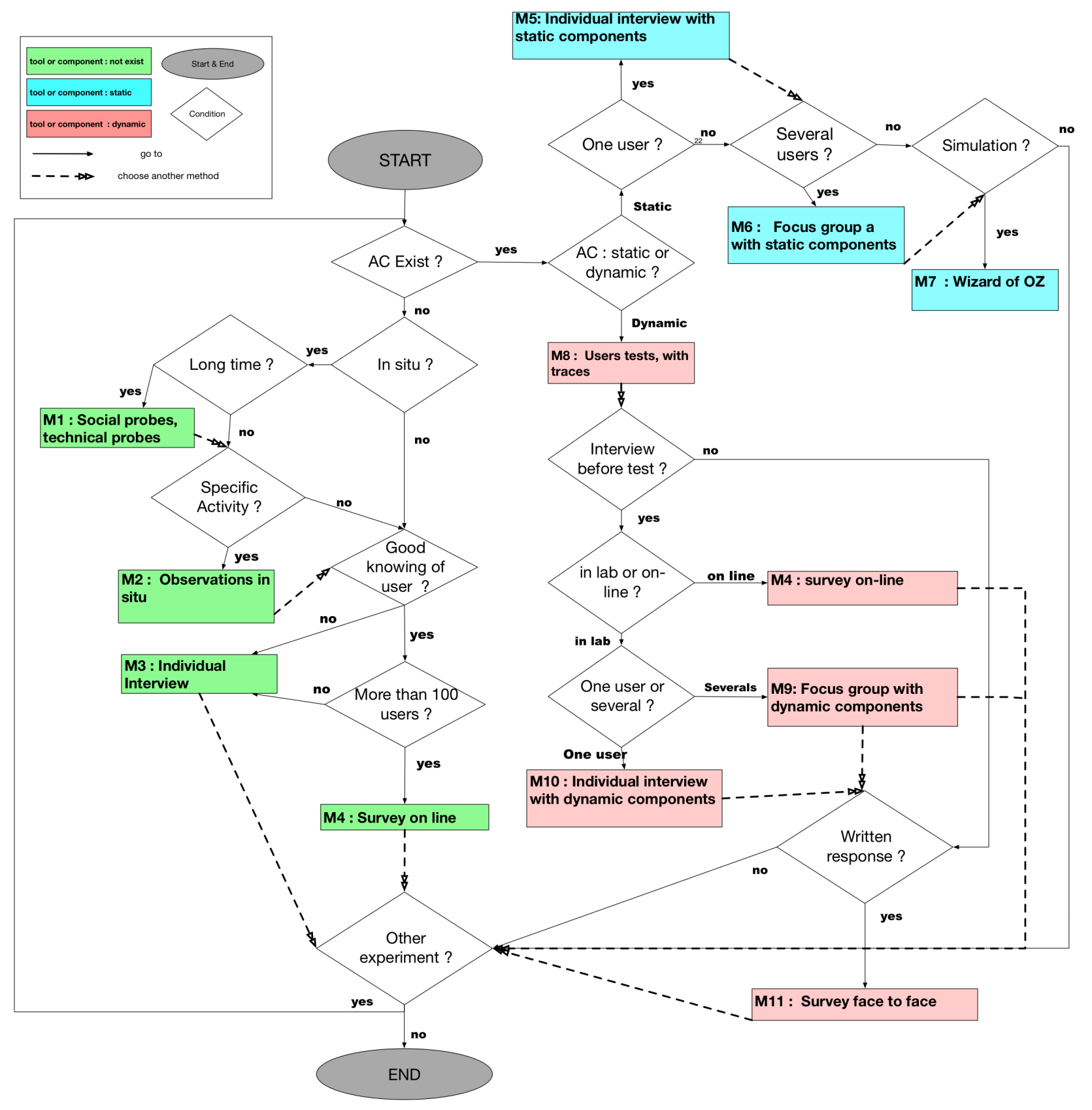

Fig.6. Decision tree MATUI

This section presented our contribution in terms of criteria and decision tree to assist researchers in the choice of the most relevant methods for producing data from users experiments. It also proposes some recommendations concerning the sample size, the experimental material, produced data and kind of data analysis in the method sheets. All these elements constitute a consistent whole for helping IS researchers in the building of their user centred experiments. To make this guidance more accessible, we developed a prototype described in the next subsection.

\section{Prototype}

To help in following the THEDRE process, particularly during the experimental steps, we developed a prototype in which researchers are guided during the process thanks to a system of question/answer. The current version of the prototype is developed in PHP with a MySQL database for the information concerning THEDRE. It does not exactly correspond the current version of THEDRE and MATUI as they have evolved after evaluation. 
A set of questions is dedicated to the selection of the user

correspond to the decision points of the MATUI tree. centred experimental method (Fig 7). These questions

\begin{tabular}{l} 
Quiz to describe step \\
This quiz helps you to describe an experimental step. You choose a pre-defined answer, then an appropriate method will be recommended \\
What is object that should be tested or studied? \\
Application \\
What is the status of object or tool ? \\
I need to explore object/tool \\
What is the way of working with subjects of experiment? \\
Alone/Face to face \\
Where the experiment can take place? \\
\hline In situ \\
What do you have to lead the experiment? \\
\hline Working prototype (maquette) \\
\hline
\end{tabular}

Fig. 7 Example of questions for selecting experimental methods

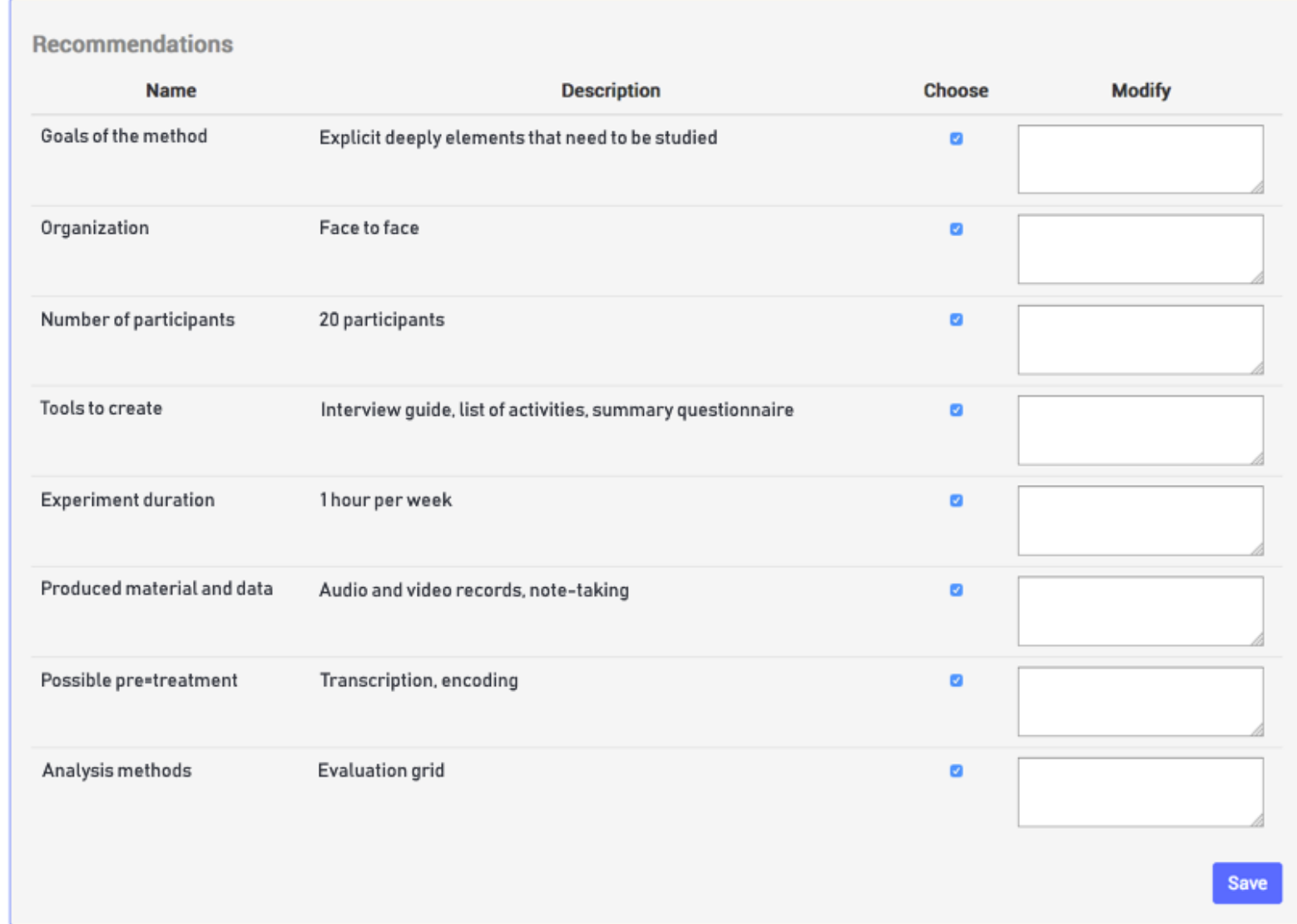

Fig. 8 Parameters for individual interviews with static activable component - Method M6. 
Once a researcher has answered to all questions, the prototype proposes a method to the researchers. For instance, if a researcher answered that he has a dynamic activable tool, a prototype, and no access to the field study and he wishes to explore her tool, the individual interview method (M10 Fig. 6) is proposed. Then the researcher can define her own parameters for her experiment with the guidance of some recommendations (Fig. 8).

\section{E. MATUI Construction and evaluation Construction}

During 10 years, we conduced experiments with researchers, particularly with $\mathrm{PhD}$ students (12 research works including $10 \mathrm{PhD}$ thesis). We identified understanding problems between researchers, developers and methodologists. We noted that researchers have troubles in identifying when and how conducing experiments and in conducing data analysis. So our research question comes from the field. The THEDRE process and to the MATUI decision tree are the results of a pragmatic and iterative work in contact with the field of IS researchers. They have been built with a participatory observation method [9]. This method consists of integrating a context while playing an active role in this context so as to understand the context and to analyse it. It allows to obtain a fine grain understanding of a field with the risk of lacking of objectivity and hindsight [21].

\section{F. Evaluation}

The THEDRE process and the MATUI tree have been evaluated with users' tests. They consist in observing users while they are testing a product and then to ask their opinions. The goal is to identify difficulties faced by users and to collect ideas to improve the product. For the THEDRE process, we evaluated its concepts and its graphical representation [8]. We also evaluated MATUI.

The MATUI decision tree was evaluated with 16 users/researchers (PhD and senior researchers) in the context of 2 focus groups. The experiments tool place in the Laboratory of Informatics of Grenoble in November 2016.

We collected participants' opinions concerning the utility and the usability of MATUI. Our hypothesis was: the MATUI decision tree for selecting user centred experimental methods is useful and useable. The activable component to evaluated was the figure describing the tree, so it was static.

Participants received the instruction to find methods from an existing research project ${ }^{3}$, which aims at developing a domain specific language and a supporting application for gardeners. The scenario was:

In the context of a botanic garden, the director of the park would like to have a tool to improve the work of the gardeners and their responsible. Gardeners will keep a track of their activities (pictures, insects met,..) to show them to their responsible. They can access to a knowledge base about products to treat trees. The responsible will manage planning and gardeners' activities. He will control the stock of product and material.

With MATUI, participants were asked to find methods to realize three types of experiments:

- Knowing gardeners' practices without knowing their activities

- Testing a mockup with garderners and their responsible

- Testing a prototype in real situation and exchange with gardeners to collect their opinions.

Participants did not have any difficulty to identify the most appropriate methods in the three types of experiments. They were able to identify several useful methods for the same experiment. For instance, for testing the prototype in real situation, two methods were identified: users test and interview.

However participants made suggestions to improve the MATUI tree. As a matter of fact, the semantics used in the tree questions were those of the methodologist and not those of IS researchers. Thus we modified the way of expressing questions.

Moreover we simplified the tree. In its first version, MATUI contained 20 questions. After the evaluation, it has only 15 . We also simplified the presentation of the tree. In the first version, methods and recommendations appeared in the schema. This overloaded it. Following participants' suggestions, we chose to present recommendations of each method independently from the tree. Now only the code of the method, such as M1, appears in the schema. Researchers have to use this code to find the description of the method.

This evaluation is mainly qualitative. We could go one step further and complete the evaluation with a quantitative experiment.

\section{COnClusions And Perspectives}

This paper proposes the THEDRE research process to guide researchers. It focuses on its experimental steps and describes a decision tree, MATUI, which helps researchers in their experimental work. MATUI is based on a categorisation of user centred experimental methods and selection criteria based on researchers' points of view. It is supported by an online tool to provide more useable guidance. Our contribution, particularly the MATUI tree, is the results of 10 years of work with researchers. It has been evaluated with two focus groups. Even if THEDRE and MATUI are used in our research laboratory, the prototype that supports them must be improved. Currently it does not reflect their current version but the one before the evaluations.

We could also provide more guidance by proposing a more specific decision tree. We could identify a typology of activable tools for some IS research domains and take them into account in the decision process to provide guidance specific to domains.
$3 \underset{\text { ANR }}{\text { MOANO }} \mathrm{http}: / /$ www.agence-nationale-
recherche.fr/?Projet=ANR-10-CORD-0024 


\section{References}

[1] F. Wang and M. J. Hannafin, 'Design-based research and technology-enhanced learning environments', Educ. Technol. Res. Dev., vol. 53, no. 4, pp. 5-23, 2005.

[2] MK Sein, O Henfridsson, S Purao, M Rossi, R Lindgren, 'Action design research', MIS quarterly, 2011.

[3] A. R. Hevner and S. Chatterjee, Design Research in Information Systems, vol. 22. Springer, 2010.

[4] J. W. Creswell, Research design: Qualitative, quantitative, and mixed methods approaches. Sage publications, 2013.

[5] P. Runeson and M. Höst, 'Guidelines for conducting and reporting case study research in software engineering', Empir. Softw. Eng., vol. 14, no. 2, pp. 131-164, Dec. 2008.

[6] P. Paille and A. Mucchielli, L'analyse qualitative en sciences humaine et sociales, 2ème ed. Armand Colin, 2011.

[7] C. Marshall and G. Rossman, Designing Qualitative Research Par Catherine Marshall,Gretchen B. Rossman. Sage publications, 2016.

[8] N. Mandran and S. Dupuy-Chessa, 'THEDRE: a Traceable Process for High Quality in Human Centred Computer Science Research', presented at the 26th International conference of System Development (ISD2017), Larnaca- Chypre, 2017.

[9] J. Copans, L'enquête ethnologique de terrain ( Ethnological field investigation). Armand Colin, 2011.

[10] E. J. De Vries, 'Rigorously Relevant Action Research in Information Systems.', in ECIS, 2007, pp. 1493-1504.

[11] A. R. Hevner, 'A three cycle view of design science research’, Scand. J. Inf. Syst., vol. 19, no. 2, p. 4, 2007.

[12] A. Hevner, Design Research in Information Systems: Theory and Practice. New York; Heidelberg u.a.: SpringerVerlag New York Inc., 2012.

[13] K. Peffers et al., 'The design science research process: a model for producing and presenting information systems research', in Proceedings of the first international conference on design science research in information systems and technology (DESRIST 2006), 2006, pp. 83-106.

[14] R. B. Jrad, M. D. Ahmed, and D. Sundaram, 'Insider Action Design Research a multi-methodological Information Systems research approach', in Research Challenges in
Information Science (RCIS), 2014 IEEE Eighth International Conference on, 2014, pp. 1-12.

[15] ISO 9241, 'ISO 9241-210:2010 - Ergonomics of human-system interaction -- Part 210: Human-centred design for interactive systems', 2010. [Online]. Available: http://www.iso.org/iso/catalogue_detail.htm?csnumber $=52075$ . [Accessed: 11-Sep-2013].

[16] W. E. Deming, 'The new economics. Massachusetts Institute of Technology', Cent. Adv. Eng. Study Camb. MA $240 p, 1993$.

[17] N. Mandran, 'THEDRE: Traceable Human Experiment Design Research', Theses, Université Grenoble Alpes, 2017.

[18] J. Nielsen, Usability Engineering. Elsevier, 1994.

[19] D. C. Howell, M. Rogier, V. Yzerbyt, and Y. Bestgen, 'Statistical Methods in Human Sciences', Boeck, 2007.

[20] J. Brooke, 'SUS-A quick and dirty usability scale', Usability Eval. Ind., vol. 189, no. 194, pp. 4-7, 1996.

[21] S. J. Taylor and R. Bogdan, 'Introduction to qualitative research methods: The search for meaning', 1984.

[23] Marco Oswaldo Santorum Gaibor, ISEA: une méthode ludique et participative pour la représentation et l'amélioration des processus métiers. (ISEA : a Ludic Collaborative Business Process Modelling and Improvement Method). Grenoble Alpes University, France 2011 (in French)

[24] R. Wieringa, Design Science Methodology for Information Systems and Software Engineering, Springer, 2014

[25] J. Venable, J. Pries-Heje, et R. Baskerville, 'A Comprehensive Framework for Evaluation in Design Science Research', in Design Science Research in Information Systems. Advances in Theory and Practice, K. Peffers, M. Rothenberger, et B. Kuechler, Ed. Berlin/Heidelberg: Springer, 2012, p. 423438.

[26] J. Venable, J. Pries-Heje, et R. Baskerville, «A Comprehensive Framework for Evaluation in Design Science Research "), in Design Science Research in Information Systems. Advances in Theory and Practice, K. Peffers, M. Rothenberger, et B. Kuechler, Ed. Berlin/Heidelberg: Springer, 2012, p. 423438. 